\title{
Economic analysis of forest insect pests in Canada
}

\author{
Kurt Niquidet, ${ }^{1}$ Jingwen Tang, Brian Peter
}

\begin{abstract}
Canada is host to a number of native and introduced forest insects that negatively affect the goods and services provided by forests. Some insects affect forests on a fairly predictable, ongoing basis, while others have impacts that are intermittent, difficult to predict, and sometimes catastrophic. Economic analysis has provided important insights that have informed our understanding of the impact of forest pests and pest management. At the same time, interactions between forests, forest insects, forest management, and economic welfare are complex, and credible assessments may be time consuming and may not always provide results with the certainty sought by policy-makers. This paper reviews the contribution of economics to forest pest management in Canada and suggests future directions for this important field of research.
\end{abstract}

\section{Introduction}

Canada is known internationally for its abundant forest resources. There are 397 million ha of forest and woodland in Canada, which represents about 9\% of the world's forest cover (Natural Resources Canada 2014). The forest sector is a key component of the Canadian economy, especially in rural areas. The total contribution of the forest products sector in 2013 was 19.8 billion Canadian dollars (constant 2007 dollars), representing about $1.25 \%$ of Canadian gross domestic product (GDP) (Natural Resources Canada 2014). Most production is destined for consumption beyond our borders, with net exports valued at 19.2 billion Canadian dollars in 2013 (Natural Resources Canada 2014). In addition to the value created by forest products, an array of ecosystem services flow from our vast forest ecosystems, such as recreation opportunities, carbon sequestration, and other services, which benefit all Canadians.

Canadian forests are constantly exposed to and impacted by a variety of natural disturbances, such as fire, wind, insects, and disease. In many of Canada's forest ecosystems, the area damaged by insects is extensive. The mountain pine beetle
(MPB), Dendroctonus ponderosae Hopkins (Coleoptera: Curculionidae), arguably casts the most negative economic impact, especially in recent years. There have been three to four largescale outbreaks of MPB in British Columbia and Alberta, Canada during the past 85 years (Taylor and Carroll 2004; Taylor et al. 2006). The current outbreak is unprecedented: killing about $50 \%$ of the commercial lodgepole pine, Pinus contorta Douglas ex Loudon (Pinaceae) in British Columbia and now extending beyond its historical range into boreal Alberta, threatening jack pine, Pinus banksiana Lambert (Pinaceae) across the boreal forest (Natural Resources Canada 2013).

Other insects that have had, or have the potential to have, significant impacts on Canadian forests include both native and non-native species. Spruce budworm (SBW), Choristoneura fumiferana (Clemens) (Lepidoptera: Tortricidae); forest tent caterpillar (FTC), Malacosoma disstria Hübner (Lepidoptera: Lasiocampidae); and various bark beetles (Coleoptera: Curculionidae: Scolytinae) frequently draw the attention of forest managers. Notable non-native species include balsam woolly adelgid, Adelges piceae (Ratzeburg) (Hemiptera: Adelgidae); Gypsy moth, Lymantria dispar

Received 24 October 2014. Accepted 10 March 2015. First published online 19 June 2015.

K. Niquidet, ${ }^{1}$ Forest Industry, Trade \& Economics Research Unit, Pacific Forestry Centre, 506 West Burnside Road, Victoria, British Columbia, Canada V8Z 1M5; and Department of Geography, University of Victoria, P.O. Box 1700, STN CSC, Victoria, British Columbia, Canada V8W 2Y2

J. Tang, B. Peter, Forest Industry, Trade \& Economics Research Unit, Pacific Forestry Centre, 506 West Burnside Road, Victoria, British Columbia, Canada V8Z 1M5

${ }^{1}$ Corresponding author (e-mail: kurt.niquidet@nrcan.gc.ca).

Langor, D.W. and Alfaro, R.I. (eds.) Forest Entomology in Canada: Celebrating a Century of Science Excellence doi: $10.4039 /$ tce. 2015.27 
(Linnaeus) (Lepidoptera: Erebidae); Sirex wood wasp, Sirex noctilio Fabricius (Hymenoptera: Siricidae); and the emerald ash borer, Agrilus planipennis Fairmaire (Coleoptera: Buprestidae).

As a result of forestry's significant contribution to the Canadian economy, forest disturbances can, and often do, have non-trivial economic impacts. The endeavour of economic analysis is to quantify these impacts in monetary terms and to weigh the costs and benefits of efforts to mitigate them. In the next section we briefly review the economic methodology that is used in forest pest management. We then review the applied literature of forest pest impacts with a focus on Canadian contributions. To conclude we identify several extant issues with economic analysis and its use in policy decisions associated with forest insect management. We hope this review will be informative to forest managers and policy-makers who need to understand the kinds of information that economic analysis can provide. Natural resource economists who are asked to support decision-makers may also find it useful to have an up-to-date review on work that has been done on the economic impacts of forest pests.

\section{Economic theory review}

Holmes et al. (2008) defined forest disturbance from an economic perspective as "an event that interrupts or impedes the flow of goods and services provided by forest ecosystems that are desired by people". This definition implies that economic impacts are viewed through an anthropocentric lens. The welfare of other species matters only to the extent that they influence the well being of humans. Indeed, the focus on people and their values is the reason why insects are considered "pests" (Liebhold 2012).

Economists' most commonly employed measure of human welfare is economic surplus, which is the difference between the benefit of the good or service and the cost to produce it. Both benefits and costs are measured in dollar values. Benefits are expressed by what people are willing to pay, which is linked to the utility they gain from acquiring the good or service. Costs, on the other hand, are a function of the opportunities that are foregone by the resources used to produce the good or service in question.

If there is a market for the forest product, the market demand curve represents the benefits and the supply curve signifies the costs, so the area between the two curves is the economic surplus.
However, market demand and supply only characterise benefits and costs that accrue to private individuals involved in market transactions. Often with forest products, there exist externalities (external costs and benefits), which fall on individuals or groups that are not party to the transaction. In theory, these externalities should be considered in the estimate of economic surplus. However, placing a value on externalities is often complex and time consuming, as it typically requires the use of various nonmarket valuation techniques. When economists reference the economic damage associated with forest disturbances, it is usually the loss in economic surplus that they are referring to. Although, as described by Holmes et al. (2009), the literature is full of examples where damages are incorrectly estimated simply by using a price-times-quantity method or by using final product values (e.g., lumber or pulp) that do not account for the opportunity cost of the resources used in bringing forest resources into production.

In addition and importantly, impacts are based on flows, making it necessary to know the different dynamics of forest production, with and without the insect, across time. It also requires the analyst to consider the time value of money, discounting future costs and benefits to a common present value. Discounting, or the level of the discount rate, often is a source of debate; in instances where costs and benefits are expected to occur far into the future (as is often the case in forestry), questions of intergenerational equity are often raised (Hepburn and Koundouri 2007; Price 2011).

Cost-benefit analysis of pest management. The next stage of economic analysis is to understand how pest management strategies influence economic damage and to conduct a cost-benefit analysis (CBA) of control efforts. The benefits of pest management are the damages that are averted (i.e., changes in economic surplus) as a result of various levels of management effort. These benefits are then compared to the cost of labour and other resources (e.g., pesticides, capital equipment) used in the control effort. Frequently analysis is restricted to a few management scenarios with the project yielding the highest net present value being recommended. However, in some instances, optimal control methods may be applied which seek to discover the control strategies that maximise the overall net benefit. Optimal control methods typically employ 
dynamic programming techniques and can be quite sophisticated (e.g., Sims et al. 2010).

A major challenge with the CBA of control is establishing a credible linkage between management interventions and the change in the flow of economic surplus from the forest (Holmes et al. 2008). As a result of significant time lags between intervention and outcomes, confounding influences are almost always present. Proper empirical examination can be data intensive and requires statistical rigour. In the absence of empirical evidence, researchers can, and often do, make simplifying assumptions. While these assumptions may have their roots in plausible bio-physical or economic theories, the lack of empirical support serves to increase the uncertainty around the benefits of control.

There are several ways to deal with uncertainty. The most common way to model uncertainty is as risk, which involves assigning probabilities to the possible outcomes of pest management. In fact, the benefits of management interventions are often associated with their reduction in the probability of an adverse outcome (Holmes et al. 2008), causing an increase in the expected economic surplus. However, uncertainty extends beyond the physical impacts of control measures on a forest estate: forest products prices and other economic parameters are volatile over time. Monte Carlo simulation is a useful tool to deal with multiple sources of uncertainty.

Cost effectiveness and threshold analysis. From an economic perspective, in an ideal world CBA should be undertaken to guide the choice of pest management programmes. In reality, a full CBA rarely occurs. Instead a programme is chosen based on a variety of goals or is simply based on historical precedent and managers are tasked with implementing the programme as effectively as possible. The target may be a given volume of timber saved, a percentage of infested trees, lowering defoliation levels in order to keep the forest green, or the population size of pests. Under such constraints, there still is a role for economic analysis. Analysis may be undertaken to achieve the programme objective in a lowest cost fashion, termed cost-effectiveness analysis (CEA). One of the computational advantages of CEA over CBA is that CEA does not require an explicit quantification of hard-to-measure programme benefits (Bicknell 1993). Alternatively, the amount of management effort may be fixed and economic analysis is conducted to uncover the threshold level of pest activity that would justify the treatment. Threshold analysis is common in pest management in agriculture but has also been done in a forestry setting (Fox et al. 1997).

Economic impact analysis. Because the forest sector is a dominant component of several regional economies across Canada, policy makers are frequently concerned about the indirect or spillover effects of the forest sector on other sectors within the region. Economic impact analysis (EIA) is sometimes employed to quantify the comprehensive damage of forest disturbances on a regional economy or the broader macro economy. Such impacts could be inter-industrial, and both forward (downstream industries) and backward (upstream industries) impacts are included. Input-output (IO) models are the most commonly used EIA method (Davis 1990). However, IO models are limited by their reliance on linear, static relationships (Lewis 1988). Furthermore, their use in the calculation of the economic damage associated with forest pests is upwardly biased, leading to an overstatement of the benefits of control (Stabler et al. 1988; Hamilton et al. 1991). Regional dynamic computable equilibrium (CGE) models are a means of overcoming the limitations of IO analysis. Nonetheless, impacts can be very sensitive to the assumptions used in CGE models, particularly with regard to the mobility and opportunity cost of factors.

\section{Canadian applications of economic analysis to forest insect management}

Economic analysis has been applied in a wide variety of studies to provide better understanding of pest disturbance and pest management in Canada. However, in the review that follows, SBW and MPB dominate the discussion. Both pests are native to the country and historically have done the most damage to the commercial forest sector in Canada. Nonetheless, non-native invasive species are increasingly seen as a threat to Canadian forests and our review also surveys the brief work that has occurred in Canada in this regard. 
Spruce budworm. The first CBA of SBW in New Brunswick, Canada was conducted in 1965 by D.A. Wilson of the Canadian Forest Service. Wilson's CBA supported a Federal-Provincial cost-sharing agreement for a spraying programme in 1965-1966 (Marshall 1975). This was followed up by a study by Marshall (1975), who also concluded that the benefits of spraying exceeded costs. However, in calculating the benefits Marshall made several questionable, simplifying assumptions. Most notably, he assumed that there were no alternative uses for inputs (labour, fuel, capital) used in forest production and consequently applied the saved valued-added in the forest sector as the benefit of control. This effectively assumes inputs cost nothing (e.g., labour is willing to work for free; manufacturing facilities can be established, maintained and run at no cost), which is not a reasonable assumption in our view.

Significant effort was then invested into understanding the timber supply impacts of the SBW and the influence of forest management, and this effort resulted in the SBW decision support system (SBW DSS) (MacLean et al. 2001). The SBW DSS has been a key input in recent economic analysis estimating both market and non-market benefits and costs of controlling hypothetical SBW outbreaks. Slaney et al. (2009) conducted an innovative study that examined the costs and benefits of protecting carbon through pest management (i.e., spraying the biological insecticide Bacillus thuringiensis Berliner (Bacillaceae)). The main feature of this study was to integrate carbon sequestration potential and carbon credit benefits into the SBW DSS. By doing so, forest managers and policy makers could then design and assess management programmes based on objectives not limited to just timber value maximisation. Twenty-four alternative scenarios were examined in two forest management units located in New Brunswick and Saskatchewan, respectively. The scenarios included two outbreak severities, three protection frequencies, and four protection area sizes. The study concluded that large-scale protection programmes were worthwhile, particularly in New Brunswick.

The same authors then conducted a similar study (Slaney et al. 2010) that incorporated timber values. Twelve SBW protection strategies were assessed on the same forest management areas: Crown License 1 in New Brunswick and the Prince Albert Forest Management Area in Saskatchewan. This study also supported intensive protections measures; however, it also revealed that smaller programmes tended to yield higher benefit-cost ratios (BCR) and were more appropriate when timber prices are low.

In a unique non-market valuation study, Chang et al. (2011) used contingent valuation to estimate the social benefits of SBW and FTC control also in Saskatchewan and New Brunswick. The results of their survey suggested that social benefits can be large, ranging between CAD\$14.3-32.4 million per year for SBW and CAD\$7.9-22.0 million for FTC. This study, along with an advanced SBW DSS model (Hennigar et al. 2013), was then used by Chang et al. (2012a) to conduct another CBA of controlling SBW in New Brunswick. The CBA evaluated six scenarios, which included three proposed protection levels and two unprotected outbreak severities. For each scenario, the net present value and BCR of market values and nonmarket values were calculated and presented. By including non-market values, CBA metrics (BCR and NPV) improved and additional control tended to be supported relative to the situations where market values were only considered.

Finally, Chang et al. (2012b) also using the SBW DSS and a dynamic CGE model conducted an EIA of future SBW outbreaks on Crown forest land in New Brunswick. This study projected the impacts over the 2012-2041 period and found that under an uncontrolled moderate SBW outbreak, total output in the New Brunswick economy would decline by 3.3 billion Canadian dollars under a moderate outbreak and 4.7 billion Canadian dollars under a severe outbreak. Aerial spraying scenarios were found to mitigate these impacts by up to $66 \%$, and harvest scheduling adjustments and salvage were found to mitigate impacts further by up to $18 \%$. The authors then stated that their findings were relevant to decision makers as they provided an understanding of both the direct and indirect impacts of SBW outbreaks on a regional economy.

Mountain pine beetle. The MPB has also received a significant amount of applied economic analysis. An early study from British Columbia by Niemann (1985) applied CEA to 
three common control strategies. The aim was to find the strategy that made best use of available funding. He argued that one should start with the cheapest control action and proceed to a more expensive action if any funds were left. He also clarified that, from an economist's point of view, wood volume at risk was not the main economic concern; it is the volume that could be saved that matters more. Further, he indicated that with more spending on detection and research, additional analysis could be conducted that would reduce the uncertainty of pest management outcomes and improve the decision making by policy makers.

Reed and Errico (1987) modelled the long-term effects of MPB at both the stand and forest-level in the Quesnel Timber Supply Area in British Columbia. At the stand level, they found that the risk of a pest infestation had very little influence on the land expectation value and the rotation age of lodgepole pine. They attribute this result to the fact that the probability of an infestation is low when stands are immature and because infested timber could be salvaged. At the forest level, they model the stochastic nature of infestations using an average annual infestation rate. While the authors recognised the limitations of this approach they showed it was reasonable over the longer term when infestation intensities were not high.

Miller et al. (1993) presented a CBA with the purpose of determining the benefits and costs of the British Columbia Ministry of Forest's control programme against the MPB. They found that the programme provided significant net benefits compared to a "no control" approach, but an enhanced programme offered little benefit when compared against the status quo.

Once the most recent MPB epidemic was underway in British Columbia, the attention of research changed from management to predicting the economic impacts that would result in the aftermath of the outbreak. Patriquin et al. (2007) developed a computable general equilibrium (CGE) model to investigate the regional economic impacts of MPB in five areas of British Columbia. The model they used was constructed on the basis of both fixed and flexible price approaches. It consisted of six producing sectors and the MPB outbreak was assumed to directly affect timber supply, which then would transfer to other industrial sectors through market activities.
The authors demonstrated that all regions were facing a short-term boost in their local economy due to increased salvage. By contrast, in the long run the areas will experience a shortage of timber supply, which will have an associated negative impact on the broader regional economy. However, in a follow up paper, Patriquin et al. (2008) showed that it may be possible to reduce the negative economic impact of the beetle on a given region by arranging an inter-temporal timber supply trade between regions. Effectively, under this reciprocal wood flow arrangement, regions that were heavily affected by the beetle could allocate their excess salvaged timber to an unaffected region. Correspondingly, the unaffected region would temporarily reduce their annual allowable cut proportionately and return timber to the affected region in the future following salvage.

As the MPB outbreak in the British Columbia Interior progressed, the forest products market was rapidly changing as a result of the financial crisis brought on by the collapse in the United States of America housing market. Schwab et al. (2009) modelled the effects of a market downturn on MPB salvage harvesting and the broader forest products industry in British Columbia. They created an agent-based model that consisted of three modules: a resource inventory module, an economic agent module, and a market module. The results projected that timber supply would be significantly reduced resulting in declining stumpage revenues and ultimately a drastically altered structure of the British Columbia forest sector.

Using a dynamic partial equilibrium trade model, Abbott et al. (2009) estimated the impact of MPB-related timber supply shortages on the forest sector. The model incorporated other changes occurring at that time to international forest products markets, namely the introduction of Russian log export taxes, and increases in plantation timber supply in the southern hemisphere and Sweden. From British Columbia's perspective, the study predicted that the most significant impacts will come from MPB-related timber supply reductions, which will constrain output but will also raise product prices somewhat.

The poor market conditions brought on by the financial crisis created concern that significant pine-beetle affected areas would go unsalvaged. Peter and Bogdanski (2010) investigated the economic case for salvage harvesting and stand 
rehabilitation in face of the MPB. They calculated stand-level net present value across a range of site conditions and treatments. The analysis showed that low-value stands with a positive outlook for natural or advance regeneration may generate greater stand value when left unsalvaged. Furthermore, where salvage harvesting was uneconomic, rehabilitation could be justified economically only on sites with high productivity, low treatment costs and a poor outlook for natural regeneration.

At the forest level, Bogle and van Kooten (2012) demonstrated how a management objective that seeks the best post-salvage inventory state can still achieve salvage objectives, while ensuring timber supplies will be there to sustain the forest sector after the salvage era is over. These same authors (Bogle and van Kooten 2013) demonstrate that the current system of deducting allowances for silviculture costs from stumpage payments has left forest companies with limited incentives to spend on silviculture, particularly when MPB-affected stands have nominal stumpage values that are less than even basic silviculture costs. Framed as a principal-agent problem, Bogle and van Kooten (2013) demonstrate how greater flexibility could reduce silviculture costs while maintaining forest productivity objectives. The study concludes that new funding mechanisms or incentives should be explored that reward efficiency in achieving silvicultural objectives.

The immense stock of degrading MPB timber also generated significant interest for bioenergy production. Using a regional wood fibre allocation model, Stennes et al. (2010) showed that expanded bioenergy production in British Columbia would not use standing MPB timber directly but instead would tend to use residuals from the primary forest sector, which had the potential to harm existing users of this fibre (e.g., pulp and pellet mills) by bidding up the price of this supply. Niquidet et al. (2012) investigated the feasibility of a large wood biomass-fired power plant designed to employ the beetle-killed pine in the Quesnel Forest District, a region at the heart of the MPB outbreak. The focus of their analysis was feedstock costs and showed that average delivered feedstock costs would increase significantly over the life of an electricity power generating facility. The sources of cost inflation were attributed to increasing transportation costs, lower quality wood, and the decreasing availability of cheap roadside residuals in the biomass supply mix over time.

Mountain pine beetle management in British Columbia is now primarily about salvage, whereas Alberta is still focussed on controlling the spread of the beetle. Mathey and Nelson (2010) studied how a resource manager could respond to potential MPB outbreaks using data from west-central Alberta in a 40-year planning exercise. A feature of their model is that it is spatially explicit and it allows for an adaptive response as information changes. The authors termed this modelling approach "planning with recourse", which involved a repeated two-step process. In the first step a management plan was generated according to a constrained net present value objective function. In the second step, forest dynamics were simulated including a stochastic beetle attack, and the forest plan was re-evaluated. They concluded that the success of a strategy was related to the age-class structure of the forest and the time horizon considered. They also found that increased harvesting levels usually paid off in improved profitability but resulted in a younger forest structure, which likely reduced other forest values such as biodiversity and wildlife habitat. They note that government will likely find it easier to implement strategies involving increased harvest levels in forests with a surplus of older stands, since these strategies also result in improved profits to firms (assuming forest product markets are also favourable).

Other native and non-native pests. One other native Canadian pest that received attention in the economic literature is jack pine budworm, Choristoneura pinus Freeman (Lepidoptera: Tortricidae). Rawat et al. (1987) attempted to optimise a single pesticide application to control this pest and studied how it may influence the optimal rotation age of jack pine in Ontario. While they noted that quantitative information was lacking for this exercise, they found that immediate pesticide application may not always be the most prudent action once the pest is noticed. Furthermore, they showed that various combinations of pest and forest conditions can drastically alter the economic rotation age.

In terms of non-native pests, Krcmar-Nozic et al. (2000) provided a detailed synthesis of research related to the potential impacts of exotic 
forest pests in North America, which included some economic impacts. However, most of the studies were derived from the United States of America. Aukema et al. (2011) provided an up-todate summary of the economic impacts of nonnative forest insects, focussing on the continental United States of America. Langor et al. (2014) describe the potential economic impacts of invasive species on Canada's boreal zone, noting that even timber impacts are not as straightforward to determine as is sometimes assumed. Nonetheless, little work has been done in Canada.

Yemshanov et al. (2009) is a unique example of a detailed Canadian study that was conducted recently. They assessed the impact of the pine woodwasp (Sirex noctilio), a new alien species detected in the United States of America in 2004 and in eastern Canada in 2005, and evaluated the feasibility of alternative harvesting policies. The analysis was conducted using the Canadian Forest Service Forest Bioeconomic Model (CFS-FBM), in which certain biophysical attributes (i.e., forest growth, timber yields, etc.) and economic analyses (i.e., timber supply and net revenue from forestry activities) were simulated. One of the main contributions of this work was incorporating detailed spatial and temporal dynamics into the analysis. Due to a lack of information about the woodwasp in Canada, an approach that was similar to a model of gypsy moth in the United States of America (Sharov and Liebhold 1998) was used to project the spread of Sirex noctilio. Four disturbance scenarios were examined along with three levels of adaptation: (1) prioritise stands by value as if the infestation did not exist (no adaptation); (2) prioritise stands by value with adjustments as the infestation progresses; and, (3) prioritise stands as in (2) but with an emphasis on harvesting stands closest to infested areas, in an effort to reduce losses. The results indicated that adaptation policies have the potential to significantly reduce economic losses. However, harvesting closer to the infestation was found to be costly in terms of increased transportation costs and harvesting of lower value stands. On the other hand, a policy with no adaptation (1) would likely result in a failure to maintain annual allowable cut levels in the future.

McKenney et al. (2012) quantified the potential economic costs to Canadian municipalities associated with emerald ash borer. Costs included those associated with the removal and replacement of affected trees, pesticide treatments to prevent damage, and overhead costs (e.g., coordination, monitoring, and communication). Scenarios varied according to the rate of spread of the pest, the discount rate and the amount of pesticide applied. Damage was shown to be potentially quite significant, ranging between CAN\$265 million to CAN\$1177 million. This led the authors to conclude that there is significant economic justification for ongoing management of the emerald ash borer.

\section{Summary and future directions}

Spruce budworm and MPB have drawn the most attention from forest economists in Canada. The analysis conducted on SBW is the most comprehensive; including cost benefit with and without timber and non-timber values as well as EIA that considers regional economic ripple effects on sectors beyond the forest industry. Much of this work was driven by the SBW DSS. While this model is comprehensive in assessing the timber supply impacts given a hypothetical level of infestation, it does not provide a forecast of future SBW population levels. Incorporating greater use of the pest's population dynamics would be beneficial in future research. This would aid in informing policy makers about the likelihood of various damage scenarios over time, and could help assess the longer-term impacts of today's management interventions. However, it must be acknowledged that forecasts generally do become more error-prone as the time horizon increases. For example, uncertainty increases around parameters used to value forests, such as forest product prices and the importance of ecosystem services to society. Future trends in forest growth and natural disturbances also become more uncertain, particularly in the face of uncertain influences from climate change. Finally, there may be future influences and events that we are currently unaware of (e.g., so called "black swan" events) that may overwhelm other assumptions used in forecasting.

The majority of economic research associated with the MPB in Canada has been focussed on salvage. This was appropriate given the recent situation in British Columbia where population levels grew so quickly and extensively that 
stopping the beetle by management efforts in most regions became infeasible. However, with the spread of the beetle into Alberta and the potential risk it poses to the boreal forest, assessments of pest management options through an economic lens are necessary. To begin this work, an assessment of the potential damage caused by further eastward spread of the MPB, using changes in economic surplus, is required. Compared to British Columbia, however, the forestland throughout the boreal region is not as commercially valuable and pine is less prevalent on the landbase. Moreover, damage is likely to be offset by salvage harvesting and could be offset further by the relaxation of annual allowable cut constraints. Consequently, damage to timber values is not expected to be large. The emphasis of analysis therefore, may need to focus on the effects of the MPB on the redistribution of timber benefits (over time and space) and on non-market values associated with the boreal forest. Quantifying the latter will be a challenging endeavour; credible estimates are more likely to be derived for values such as recreation, water and carbon where market or physical linkages exist. Stated preference methods used to uncover non-use values (e.g., existence value) on the other hand can be controversial and are subject to several well known biases (Birol et al. 2006). While this should not deter research in this area, good practice guidelines need to be followed to alleviate valuation concerns as much as possible (Riera et al. 2012).

In addition to valuation studies, credible CBA of the MPB requires more information about the effect of management on spread rates. Development in this area could also spur new bioeconomic applications that use optimal control methods. At the forefront of this research is spatial optimisation (Aadland et al. 2013), although this type of work tends to be computationally intensive particularly if one wants to make the model operational at a larger landscape level.

Holmes (2010) also called for greater integration of spatial processes in the modelling of nonnative insects. Yemshanov et al. (2009) could act as a study template for research on other potential invasive pests threatening Canadian forests, although more work could be done to incorporate uncertainty in spread rates. Here, modelling uncertainty as risk - as is typical in many economic applications - would be subjective and open to critique given the lack of historical precedent (Horan et al. 2002). The application of innovative methods to deal with uncertainty of pest establishment and spread would be welcome additions to this field (e.g., Kangas and Kangas 2004; Hildebrandt and Knoke 2011; Williamson et al. 2011). One avenue that could be explored further is the linkage between trade and other economic processes and the likelihood of invasive pest establishment, such as has been done by Taylor and Irwin (2004) for invasive plants.

To close, economists can help quantify the changes in economic well being that may be induced as a result of insect infestations and weigh the costs and benefits of various management actions. However, policy makers often are looking for results on a short time frame. Proper assessments can be complex and require significant time and resources and collaboration with other scientific disciplines. Policy-makers are also interested in economic metrics that may not be consistent with welfare economics and CBA. For example, forest sector job losses resulting from forest insect damage may lead to economic welfare changes, though these are complex and can be much less severe than is sometimes assumed (Hamilton et al. 1991). Furthermore, high levels of uncertainty over insect behaviour, control efficacy, and biophysical impacts will almost always translate into high levels of uncertainty over economic impacts and the net economic benefits of control. Science (social and physical) policy integration will continue to be a key challenge in forest insect management going forward.

\section{Acknowledgements}

The authors would like to thank Alec McBeath and two anonymous reviewers for their helpful comments on earlier drafts of this article.

\section{References}

Aadland, D., Sims, C., and Finnoff, D. 2013. Spatial dynamics of optimal management in bioeconomic systems. Available from http://www.uwyo.edu/ aadland/research/spatialmpb.pdf [accessed 11 April 2013].

Abbott, B., Stennes, B., and van Kooten, G.C. 2009. Mountain pine beetle, global markets, and the British Columbia economy. Canadian Journal of Forest Research, 39: 1313-1321. 
Aukema, J.E., Leung, B., Kovacs, K., Chivers, C., Britton, C.O., Englin, J., et al. 2011. Economic impacts of non-native forest insects in the continental United States. Public Library of Science One, 6: e24587.

Bicknell, K. 1993. Cost-benefit and cost-effectiveness analyses in pest management. New Zealand Journal of Zoology, 20: 307-312.

Birol, E., Karousakis, K., and Koundouri, P. 2006. Using economic valuation techniques to inform water resources management: a survey and critical appraisal of available techniques and an application. Science of the Total Environment, 365: 105-122.

Bogle, T. and van Kooten, G.C. 2012. Why mountain pine beetle exacerbates a principal-agent relationship: exploring strategic policy responses to beetle attack in a mixed species forest. Canadian Journal of Forest Research, 42: 621-630.

Bogle, T. and van Kooten, G.C. 2013. Options for maintaining forest stand productivity after natural disturbance: a principal-agent approach. Forest Policy and Economics, 26: 138-144.

Chang, W.Y., Lantz, V.A., Hennigar, C.R., and MacLean, D.A. 2012a. Benefit-cost analysis of spruce budworm (Choristoneura fumiferana Clem.) control: incorporating market and non-market values. Journal of Environmental Management, 93: 104-122.

Chang, W., Lantz, V.A., Hennigar, C.R., and MacLean, D.A. 2012b. Economic impacts of forest pests: a case study of spruce budworm outbreaks and control in New Brunswick, Canada. Canadian Journal of Forest Research, 42: 490-505.

Chang, W.Y., Lantz, V.A., and MacLean, D.A. 2011. Social benefits of controlling forest insect outbreaks: a contingent valuation analysis in two Canadian provinces. Canadian Journal of Agricultural Economics, 59: 383-404.

Davis, H.C. 1990. Regional economic impact analysis and project evaluation. UBC Press, Vancouver, British Columbia, Canada.

Fox, G., Beke, J., Hopkin, T., and McKenney, D. 1997. A framework for the use of economic thresholds in forest pest management. The Forestry Chronicle, 73: 331-339.

Hamilton, J.R., Whittlesey, N.K., Robison, M.H., and Ellis, J. 1991. Economic impacts, value added, and benefits in regional project analysis. American Journal of Agricultural Economics, 73: 334-344.

Hennigar, C.R., Erdle, T.A., Gullison, J.J., and MacLean, D.A. 2013. Re-examining wood supply in light of future spruce budworm outbreaks: a case study in New Brunswick. The Forestry Chronicle, 89: 42-53.

Hepburn, C. and Koundouri, P. 2007. Recent advances in discounting: implications for forest economics. Journal of Forest Economics, 13: 169-189.

Hildebrandt, P. and Knoke, T. 2011. Investment decisions under uncertainty - a methodological review on forest science studies. Forest Policy and Economics, 13: 1-15.
Holmes, T.P. 2010. Confronting challenges to economic analysis of biological invasions in forests. New Zealand Journal of Forestry Science, 40: S105S116.

Holmes, T.P., Aukema, J.E., von Holle, B., Liebhold, A., and Sills, E. 2009. Economic impacts of invasive species in forests: past, present and future. Annals of the New York Academy of Sciences, 1162: 18-38.

Holmes, T.P., Prestemon., J.P., and Abt, K.L. 2008. The economics of forest disturbances: wildfires, storms and invasive species. Forestry Sciences, Springer, Dordrecht, The Netherlands.

Horan, R.D., Perrings, C., Lupi, F., and Bulte, E.H. 2002. Biological pollution prevention strategies under ignorance: the case of invasive species. American Journal of Agricultural Economics, 84: 1304-1310.

Kangas, A. and Kangas, J. 2004. Probability, possibility and evidence: approaches to consider risk and uncertainty in forestry decision analysis. Forest Policy and Economics, 6: 169-188.

Krcmar-Nozic, E., Wilson, B., and Arthur, L. 2000. The potential impacts of exotic pests in North America: a synthesis of research. Information Report BC-X-387. Natural Resources Canada, Canadian Forest Service, Pacific Forestry Centre, Victoria, British Columbia, Canada.

Langor, D.W., Cameron, E.K., MacQuarrie, C.J.K., McBeath, A., McClay, A.S., Peter, B., et al. 2014. Nonnative species in Canada's boreal zone: diversity, impacts and risk. Environmental Reviews, 22: 372-420.

Lewis, J.A. 1988. Economic impact analysis: a U.K. literature survey and bibliography. Progress in Planning, 30: 157-209.

Liebhold, A.M. 2012. Forest pest management in a changing world. International Journal of Pest Management, 58: 289-295.

MacLean, D.A., Erdle, T.A., MacKinnon, W.E., Porter, K.B., Beaton, K.P., Cormier, G., et al. 2001. The spruce budworm decision support system: forest protection planning to sustain long-term wood supply. Canadian Journal of Forest Research, 31: 1742-1757.

Marshall, K.B. 1975. The spruce budworm and the dollar in New Brunswick. The Forestry Chronicle, 8: 143-146.

Mathey, A.H. and Nelson, H. 2010. Assessing forest management strategies under a mountain pine beetle attack in Alberta: exploring the impacts. Canadian Journal of Forest Research, 40: 597-610.

McKenney, D.W., Pedlar, J.H., Yemshanov, D., Lyons, D.B., Campbell, K.L., and Lawrence, K. 2012. Estimates of the potential cost of emerald ash borer (Agrilus planipennis Fairmaire) in Canadian municipalities. Aboriculture \& Urban Forestry, 38: 81-91.

Miller, D.R., Carlson, J.A., and Stemeroff, M. 1993. Socioeconomic analysis of mountain pine beetle management in British Columbia. Phero Tech Inc., Delta, British Columbia, Canada. Available from http://www.for.gov.bc.ca/hfd/library/documents/ bib45971.pdf [accessed 11 April 2013]. 
Natural Resources Canada. 2013. The threat of mountain pine beetle to Canada's boreal forest. Available from http://www.nrcan.gc.ca/forests/insects-diseases/ 13381 [accessed 22 August 2013].

Natural Resources Canada. 2014. The state of Canada's forests annual report 2014. Natural Resources Canada, Ottawa, Ontario, Canada. Available from https://cfs. nrcan.gc.ca/publications?id=35713 [accessed 7 April 2015].

Niemann, T. 1985. Cost benefit analysis and other economic decision-making processes in assessing and selecting beetle management options. In Mountain pine beetle symposium proceedings. Edited by P.M. Hall and T.F. Maher. British Columbia Ministry of Forests, Prince Rupert Region. Pest Management Report Number 7: 128-150. Available from http://www.for.gov.bc.ca/hfd/ library/MPB/bib35416.pdf [accessed on 11 April 2013].

Niquidet, K., Stennes, B., and van Kooten, G.C. 2012. Bioenergy from mountain pine beetle timber and forest residuals: a cost analysis. Canadian Journal of Agricultural Economics, 60: 195-210.

Patriquin, M.N., Lantz, V.A., Stedman, R.C., and White, W.A. 2008. Working together: a reciprocal wood flow arrangement to mitigate the economic impacts of natural disturbance. Forestry, 81: 227-242.

Patriquin, M.N., Wellstead, A.M., and White, W.A. 2007. Beetles, trees, and people: regional economic impact sensitivity and policy considerations related to the mountain pine beetle infestation in British Columbia, Canada. Forest Policy and Economics, 9: 938-946.

Peter, B. and Bogdanski, B. 2010. The economics of salvage harvesting and reforestation in British Columbia's mountain pine beetle-affected forests. Information Report BC-X-425. Canadian Forest Service, Pacific Forestry Centre, Victoria, British Columbia, Canada.

Price, C. 2011. Optimal rotation with declining discount rate. Journal of Forest Economics, 17: 307-318.

Rawat, J.K., Belli, K.L., Smith, S.M., and Nautiyal, J.C. 1987. A pest and timber management model: jack pine budworm and jack pine. Canadian Journal of Agricultural Economics, 35: 441-461.

Reed, W.J. and Errico, D. 1987. Techniques for assessing the effects of pest hazards on long-run timber supply. Canadian Journal of Forest Research, 17: 1455-1465.

Riera, P., Signorello, G., Thiene, M., Mahieu, P.A., Navrud, S., Kaval, P., et al. 2012. Non-market valuation of forest goods and services: good practice guidelines. Journal of Forest Economics, 18: 259-270.

Schwab, O., Maness, T., Bull, G., and Roberts, D. 2009. Modeling the effect of changing market conditions on mountain pine beetle salvage harvesting and structural changes in the British Columbia forest products industry. Canadian Journal of Forest Research, 39: 1806-1820.
Sharov, A.A. and Liebhold, A.M. 1998. Model of slowing the spread of gypsy moth (Lepidoptera: Lymantriidae) with a barrier zone. Ecological Society of America, 8: 1170-1179.

Sims, C., Aadland, D., and Finnoff, D. 2010. A dynamic bioeconomic analysis of mountain pine beetle epidemics. Journal of Economic Dynamics \& Control, 34: 2407-2419.

Slaney, G.L., Lantz, V.A., and MacLean, D.A. 2009. The economics of carbon sequestration through pest management: application to forested land bases in New Brunswick and Saskatchewan, Canada. Forest Policy and Economics, 11: 525-534.

Slaney, G.L., Lantz, V.A., and MacLean, D.A. 2010. Assessing costs and benefits of pest management on forested landbases in eastern and western Canada. Journal of Forest Economics, 16: 19-34.

Stabler, J.C., van Kooten, G.C., and Meyer, N. 1988. Methodological issues in appraisal of regional resource development projects. Annals of Regional Science, 22: 13-25.

Stennes, B., Niquidet, K., and van Kooten, G.C. 2010. Implications of expanding bioenergy opportunities from wood in British Columbia: an application of a regional wood fiber allocation model. Forest Science, 56: 366-378.

Taylor, B. and Irwin, R. 2004. Linking economic activities to the distribution of exotic plants. Environmental Science, 101: 17725-17730.

Taylor, S.W. and Carroll, A.L. 2004. Disturbance, forest age, and mountain pine beetle outbreak dynamics in BC: a historical perspective. In Mountain pine beetle symposium: challenges and solutions, Kelowna, British Columbia. 30-31 October 2003, Information Report BC-X-399. Edited by T.L. Shore, J.E. Brooks, and J.E. Stone. Natural Resources Canada, Canadian Forest Service, Pacific Forestry Centre, Victoria, British Columbia, Canada. Pp. 41-51.

Taylor, S.W., Carroll, A.L., Alfaro, R.I., and Safranyik, L. 2006. Forest, climate and mountain pine beetle outbreak dynamics in western Canada. In The mountain pine beetle: a synthesis of biology, management and impacts on lodgepole pine. Edited by L. Safranyik and W. Wilson. Natural Resources Canada, Canadian Forest Service, Pacific Forestry Centre, Victoria, British Columbia, Canada. Pp. 67-94.

Williamson, T., Luckert, M., and Hauer, G. 2011. Economic concepts, methods, and tools for risk analysis in forestry under climate change. In Environmental modeling for sustainable regional development: system approaches and advanced methods. Edited by V. Olej, I. Obršalová, and J. Krupa. IGI Global, Hershey, Pennsylvania, United States of America. Pp. 303-326.

Yemshanov, D., McKenney, D.W., de Groot, P., Haugen, D., Sidders, D., and Joss, B. 2009. A bioeconomic approach to assess the impact of an alien invasive insect on timber supply and harvesting: a case study with Sirex noctilio in eastern Canada. Canadian Journal of Forest Research, 39: 154-168. 